\title{
Botrytis allii Munn -sienen infektoituminen sipuliin kas- vukaudella ja sadonkorjuun aikana
}

\author{
RISTO TAHVONEN
}

Helsingin yliopiston kasvipatologian laitos

SF-00710 Helsinki 71

Uusi osoite: Maatalouden tutkimuskeskus, kasvitautiosasto, 31600 Jokioinen

Botrytis allii Munn infection of onion during the growing season and harvesting in Finland

\section{Risto Tahvonen}

Department of Plant Pathology, University of Helsinki

New address: Agricultural Research Centre, Institute of Plant Pathology, SF-31600 Jokioinen, Finland

Abstract. Botrytis allii Munn infected onions growing in heavily-inoculated soil in one year during trials lasting for three years. Late harvesting only slightly increased the $B$. allii content of the yield. The completely mechanized harvesting method and fungicide sprayings before harvesting had no effect on the B. allii $-\%$ of the yield, when the onion leaves were either left intact or cut off $10-15 \mathrm{~cm}$ above the neck and the onions dried immediately after lifting.

\section{Johdanto}

Useissa viime vuosina tehdyissä tutkimuksissa on todettu, että Botrytis allii Munn -sienen leviäminen kasvukaudesta toiseen tapahtuu pääasiassa siemen- tai istukassaastuntana ja että kasvukaudella sieni on sipuleissa piilevänä eikä leviä yleensä tänä aikana merkittävästi terveisiin kasveihin (BRÄUTIGAM 1977, MAUDE ja PRESLY 1977a, b, BOCHOW ja BÖTTCHER 1978, BOCHOW ja EL-MOSALLAMY 1979, JANÝŠKA ja ROD 1980, ROD ja JANÝŠKA 1980, TAHVONEN 1981). Kuitenkin vanhemmissa lähdeteoksissa kerrotaan taudin leviävän esimerkiksi maassa säilyneistä rihmastopahkoista sipuleihin tuleentumisen jälkeen ja sadonkorjuun yhteydessä (WALKER 1952, HEINZE 1974).

Koska Suomessa on loppukesällä ja syksyllä usein viileää ja kosteaa, ovat olosuhteet erinomaiset sipulien kasvukautiselle $B$. allii -saastunnalle. Tämän takia haluttiin istukaslevintään liittyvien tutkimusten ohella selvittää taudin

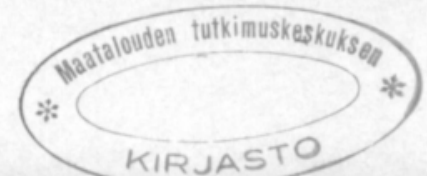


leviämistä voimakkaasti saastuneesta maasta ja testata $B$. allii -sienen leviämismahdollisuuksia hyvin myöhäisessä ja koneellistetussa sadonkorjuussa, jossa mekaanisten vioitusten syntyminen on yleistä.

\section{Aineisto ja menetelmät}

Vuosina 1978-80 levitettiin vuosittain samalle paikalle $\mathrm{n} .1 \mathrm{~kg} / \mathrm{m}^{2}$ muista sipulikokeista tulleita Botrytis allii Munn -sienen saastuttamia sipuleita, jotka muokattiin $\mathrm{n} .5 \mathrm{~cm}: n$ syvyiseen kerrokseen. Tälle voimakkaasti saastutetulle alueelle ja samalle peltolohkolle $100-200 \mathrm{~m}$ päähän, jossa ei aikaisemmin oltu kasvatettu sipulia, istutettiin käsittelemättömiä ja 15 min. $0.1 \%$ :ssa benomyylissä liotettuja 'Stuttgarter Riesen' sipulin pikkuistukkaita. Saastutetulla alueella benomyyliliotuksen lisäksi sipuleita ruiskutettiin benomyylillä (0.6 $\mathrm{kg} / \mathrm{ha}$ ), kun sipulin lehdet olivat kasvaneet $10-15 \mathrm{~cm}$ :n pituisiksi. Käsittely uusittiin osalle sipuleista 2 viikon kuluttua. Kokeet toistettiin kolmena kerranteena.

Vuosina 1979-80 tehtiin nostoaikakoe, jossa ensimmäinen sadonkorjuu tehtiin elokuun puolivälissä ja siitä eteenpäin $10 \mathrm{vrk}$ :n välein syyskuun loppuun tai lokakuun alkuun asti. Yksi viikko ennen sadonkorjuuta osa nostettavista sipuleista ruiskutettiin benomyylillä $(0.6 \mathrm{~kg} / \mathrm{ha})$. Sadonkorjuussa sipuleita ravisteltiin voimakkaasti puulaatikoissa, millä pyrittiin jäljittelemään koneellisen sadonkorjuun aiheuttamia kolhuja. Koe toistettiin neljänä kerranteena siten että jokaisessa kerranteessa oli alkuperältään eri istukaserä.

Vuosina 1979-80 järjestettiin käsin- ja konenoston välinen vertailukoe eräällä käytännön viljelmällä, jossa sadonkorjuuvaiheet oli koneellistettu täysin nostosta varastointiin asti. Varovaisen käsinnoston lisäksi otettiin sipulinäytteet koneellisen sadonkorjuuketjun päättyessä viimeiseltä elevaattorilta sipulien pudotessa lopulliselle varastointipaikalleen. Vuonna 1979 käsittelemättömän sipulin lisäksi oli mukana yksi viikko ennen sadonkorjuuta benomyylillä $(0.6 \mathrm{~kg} / \mathrm{ha})$ tai vinklozolinilla $(1.05 \mathrm{~kg} / \mathrm{ha})$ ruiskutetut sipulit. Vuonna 1980 oli kone- ja käsinnoston vertailussa kolme nostoaikaa (25. 8., 2. 9. ja 17. 9.). Jokaisesta koejäsenestä otettiin neljä rinnakkaisnäytettä.

Kasvukausista v. 1978 oli normaalia kylmempi ja sateisempi, ja vuosina 1979-80 olivat lämpötila ja sademäärät lähellä pitkäaikaisia keskiarvoja. Sipulien varastointi ja tautimääritykset olivat samanlaiset kuin aikaisemmin esitetyissä tutkimuksissa (TAHVONEN 1981).

\section{Tulokset ja tulosten tarkastelu}

Botrytis allii Munn infektoi sipuleita saastutetussa pellossa ensimmäisenä koevuotena $1.2-5.8 \%$ ja toisena $0-2.5 \%$ verrattuna terveeseen peltoon. Kolmantena koevuotena maasta tapahtuva saastunta nousi $30 \%$ :iin (taulukko 1). Saastutetulle alueelle levitettiin koevuosien aikana yhteensä n. 30 
Taulukko 1. Sipulin Botrytis allii -saastunta vuosittain peltoon sekoitetuista kasvijätteistä.

Table 1. Infection of onions by Botrytis allii in soil contaminated every year with onion debris.

Sipuleiden B. allii- $\%$ varastossa $-B$. allii $-\%$ of bulbs in store

\begin{tabular}{|c|c|c|c|c|c|c|c|}
\hline \multirow[b]{2}{*}{0} & \multicolumn{2}{|c|}{$\begin{array}{l}\text { saastutettu maa } \\
\text { inoculated soil }\end{array}$} & \multirow[b]{2}{*}{3} & & \multicolumn{2}{|c|}{$\begin{array}{l}\text { terve maa } \\
\text { bealthy soil }\end{array}$} & \\
\hline & 1 & 2 & & & 0 & 1 & \\
\hline & & & & 1978 & & & \\
\hline 12.6 & 4.1 & - & 4.6 & 1979 & 6.8 & 2.9 & $\mathrm{~F}=5.2^{2 * 414}, \mathrm{LSD}_{\mathrm{t0.05} *}=5.4$ \\
\hline 9.2 & 6.6 & 8.3 & 7.3 & 1980 & 9.2 & 4.1 & $\mathrm{~F}<1$ \\
\hline 34.2 & 33.2 & 25.7 & 22.1 & & 6.8 & 2.3 & $F=14.6^{* 4 * 4}, L_{S S D}{ }_{40.05} \%=10.6$ \\
\hline
\end{tabular}

$0=$ käsittelemätön istukas, $1=$ benomyyli-liotettu istukas, $2=$ benomyyli-liotettu istukas +1 benomyyliruiskutus keväällä, $2=$ benomyyli-liotettu istukas +2 benomyyliruiskutusta keväällä

$0=$ untreated set, $1=$ benomyl soaked set, $2=$ benomyl soaked set +1 benomyl spraying in spring, $3=$ benomyl soaked set +2 benomyl sprayings in spring

Taulukko 2. Sadonkorjuuajan ja viikkoa ennen sadonkorjuuta tehdyn benomyyli-ruiskutuksen vaikutus sipulin Botrytis allii -pitoisuuksiin.

Table 2. The effect of harvesting time and benomyl spraying one week before harvesting on the Botrytis allii -content of onion.

Sipuleiden $B$. allii -\% varastossa $-B$. allii $-\%$ of bulbs in store

Sadonkorjuupäivät v. 1979

Harvesting dates in 1979

$\begin{array}{llllll}\text { 15.8. 24.8. } & \text { 3.9. } & \text { 13.9. 24.9. 2.10. } & \hat{\mathrm{X}}\end{array}$

Käsittelemätön

Untreated

\begin{tabular}{|c|c|c|c|c|c|}
\hline 0.6 & 0.0 & 1.1 & 0.0 & 0.3 & 0.3 \\
\hline 0.5 & 0.0 & 2.5 & 0.5 & 0.0 & 0.6 \\
\hline$\overline{\mathrm{X}} 0.6$ & 0.0 & 1.8 & 0.3 & 0.2 & 0.5 \\
\hline
\end{tabular}

Benomyyli-ruiskutus

Benomyl spraying

Sadonkorjuupäivät v. 1980

Harvesting dates in 1980

$\begin{array}{llll}\text { 18.8. } & 28.8 & 8.9 . & 18.9\end{array}$

29.9 .

$\overline{\mathrm{X}}$

Käsittelemätön

Untreated

\begin{tabular}{cccccc}
1.0 & 1.2 & 10.8 & 6.7 & 10.4 & 6.0 \\
1.6 & 0.7 & 6.3 & 10.8 & 12.4 & 6.4 \\
\hline $\bar{X} 1.3$ & 1.0 & 8.4 & 8.8 & 11.4 & \\
\hline
\end{tabular}

Benomyyli-ruiskutus

Benomyl spraying

F-arvot: 1979: $<1,1980$ : kertaukset $($ istukaserät $)=10.9^{n}$, ruiskutus $=0.1$, nostoaika $=3.9^{n}$, yhteisvaikutus $=0.5$

F-values: 1979: $<1,1980$ : replications (onion set lots) $=10.9^{n}$, spraying $=0.1$, lifting time $=3.9^{n}$, combined effect $=0.5$ 
tn/ha $B$. allii -sienen pilaamia sipuleita kevätmuokkausten yhteydessä. Tämä määrä on niin iso, että käytännössä ei koskaan voi tulla näin suurta saastuntatiheyttä maahan. $B$. allii -sienen on todettu muissa tutkimuksissa häviävän maasta kahdessa vuodessa (MAUDE ym. 1982). Näiden tulosten perusteella tämän sienen maasaastunnalla ei ole merkitystä käytännön viljelmillä, joilla ei viedä sairaita sipuleita takaisin peltoon ja joilla pyritään noudattamaan mahdollisuuksien mukaan sipulinviljelyn vaatimaa $3-4$ vuoden viljelykiertoa.

Sadonkorjuuajalla ei vuonna 1979 ollut vaikutusta sipulin $B$. allii -pitoisuuksiin. Seuraavana vuotena myöhäisimmät sadonkorjuuajat lisäsivät varastoidun sipulin $B$. allii -pitoisuutta Viikissä 7-10\% ja käytännön viljelmällä alle $2.5 \%$ (taulukko 2 ja 4). Korkeimmat tautipitoisuudet olivat vain tiettyä alkuperää olevissa sipuleissa, mikä viittaa taudin runsauden olevan enemmän riippuvainen istukkaan terveydestä (vert. ROD ja JANÝŠKA 1980, TAHVONEN 1981) kuin sadonkorjuuajasta. Sipulin oma puolustusmekanismi $B$. allii -sientä vastaan, keltainen kuori (HATFIELD ym. 1948) ja solukon eri osien kestävyyserot (BOCHOW ja EL-MOSALLAMY 1979), suojaa ilmeisesti kasvukauden lopussa tehokkaasti sieni-infektiota vastaan huonoissakin olosuhteissa. Tästä oli jo aiemmin saatu Suomen olosuhteissa selviä tuloksia, kun kasvukauden lopulla oli tehty keinosaastutuksia (TAHVONEN 1981).

Täysin koneellistetulla sadonkorjuuketjulla ei näytä olevan merkitystä varastoidun sipulin $B$. allii -pitoisuuksiin (taulukko 3 ja 4). Nykyisin Suomessa omaksutussa sadonkorjuukäytännössä sipuleita ei listitä tai listintä tehdään $10-15 \mathrm{~cm}$ niskan yläpuolelta. Sadon keinokuivatus aloitetaan välittömästi noston jälkeen, jolloin sipuleihin muodostuu nopeasti suojaava kuiva kuori mahdollista ulkoista $B$. allii -saastuntaa vastaan. Ilmeisesti tämän takia ennen sadonkorjuuta tehdyt fungisidiruiskutukset olivat merkityksettömiä (taulukko 2 ja 3), kuten jo aiemmissakin tutkimuksissa oli todettu (TAHVONEN 1981).

Taulukko 3. Fungisidiruiskutusten vaikutus koneella tai käsin nostetun sipulin Botrytis allii -pitoisuuksiin v. 1979.

Table 3. The effect of fungicide sprayings on the Botrytis allii content of onions lifted by harvesting machine or hand in 1979.

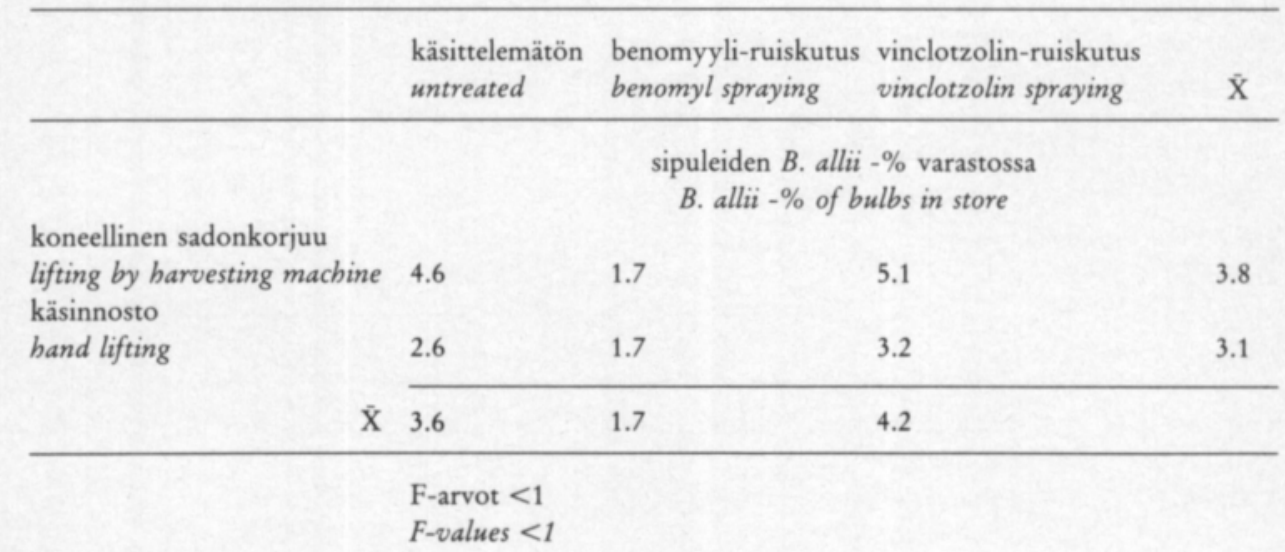


Taulukko 4. Koneellisen sadonkorjuun tai käsinnoston vaikutus eri sadonkorjuuaikoina sipulin Botrytis allii -pitoisuuksiin.

Table 4. The effect of harvesting machine or hand lifting at different harvesting times on the Botrytis allii content of onions.

\begin{tabular}{lll}
\hline sadonkorjuuaika & koneellinen nosto & käsinnosto \\
harvesting dates & lifting by harvesting machine & hand lifting \\
\hline
\end{tabular}

\begin{tabular}{rr}
0.7 & 0.7 \\
0.7 & 0.5 \\
2.1 & 2.1 \\
\hline$\overline{\mathrm{x}} 1.2$ & 1.1 \\
\hline
\end{tabular}

F-arvot $<1$

F-values $<1$

\section{Tiivistelmä}

Vuosina 1978-80 tehdyissä sipulin varastotautitutkimuksissa haluttiin hyvin tärkeäksi todetun istukaslevinnän lisäksi tarkistaa sipulin tärkeimmän varastotaudin, Botrytis allii Munn -sienen mahdollisuutta saastuttaa sipulia kasvukaudella ja sadonkorjuun yhteydessä, mitä seikkaa vanhemmassa kirjallisuudessa on painotettu.

Samaan peltolohkoon muokattiin kolmena vuotena peräkkäin edellisenä varastokautena kokeista tulleita sairaita sipuleita n. $10 \mathrm{tn} / \mathrm{ha} / \mathrm{v}$. Tässä voimakkaasti saastuneessa maassa ja samalla peltoaukeamalla 100-200 m:n etäisyydellä kasvatettiin sipuleita maasta tapahtuvan saastunnan toteamiseksi. Toisessa kokeessa sipulisatoa korjattiin elokuun puolivälistä syyskuun loppuun kymmenen vuorokauden välein. Osa korjatuista sipuleista ruiskutettiin yksi viikko ennen nostoa benomyylillä. Kolmannessa kokeessa verrattiin koneellisesti ja käsin nostetun sipulisadon $B$. allii -pitoisuuksia toisiinsa.

$B$. allii -sieni saastutti sipuleita maasta käsin vasta kolmantena koevuotena. Myöhäinen sadonkorjuuaika lisäsi vain lievästi sadon harmaahomeisuutta. Jos käytetty istukas oli tervettä, ei myöhäisellä sadonkorjuulla ollut vaikutusta tautisuuteen. Yksi viikko ennen sadonkorjuuta tehdyillä fungisidiruiskutuksilla ei ollut vaikutusta $B$. allii -pitoisuuksiin. Koneellinen sadonkorjuuketju pellolta varastoon ei näyttänyt lisäävän sipulin harmaahometta käsinnostoon verrattuna.

\section{Kirjallisuusluettelo}

BOCHOW, H. \& BÖTTCHER, H. 1978. Zur Bekämpfung von Botrytis allii Munn durch Einsatz von Fungiziden. Nachr.bl. Pfl.schutz 32: 135-137.

— \& EL-MOSALLAMY, H. M. 1979. Untersuchungen zum Befallsverhalten von Botrytis allii Munn bei Allium cepa L. Arch. Phytopath. Pfl.schutz 15: 103-112. 
BRÄUTIGAM, S. 1977. Botrytis allii Munn an Zwiebelsaatgut. Nachr.bl. Pfl.schutz DDR 31: 195.

HATFIELD, W. C., OWEN, J. H. \& WALKER, J. C. 1948. Antibiotic substances in onion in relation to disease resistance. J. Agr. Res. 77: 115-135.

HEINZE, K. 1974. Leitfaden der Schädlingsbekämpfung. I. Schädlinge und Krankheiten im Gemüsebau. 360 p. Stuttgart.

JANÝSKKA, A. \& ROD, J. 1980. Vliv mořeni osiva cibule kuchyňske (Allium cepa $L$ ) na vynosy a výskyt króčkové hniloby. Sbor. ÚVTIZ - Zahradnictví 7: 197-208.

MAUDE, R. B. \& PRESLY, A. H. 1977a. Neck rot (Botrytis allii) of bulb onions. I. Seed-borne infection and its relationship to the disease in the onion crop. Ann. Appl. Biol. 86: 163-180.

- \& PRESLY, A. H. 1977b. Neck rot (Botrytis allii) of bulb onions. II. Seed-borne infection in relationship to the disease in store and the effect of seed treatment. Ann. Appl. Biol. 86: 181-188.

-, BAMBRIDGE, J. M. \& PRESLY, A. H. 1982. The persistence of Botrytis allii in field soil. Pl. Path. 31: 247-252.

ROD, J. \& JANÝŠKA, A. 1980. Ochrana cubule kuchyňské (Allium cepa L.) ze sazečky proti Botrytis allii Munn. Sbor. ÚVTIZ - Zahradnictví 7: 279-288.

TAHVONEN, R. 1981. Storage fungi of onion and their control. J. Scient. Agr. Soc. Finl. 53: 27-41.

WALKER, J. C. 1952. Diseases of vegetable crops. 529 p. New York, Toronto, London.

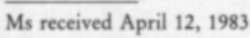

